Bundesgesundheitsbl 2014 · 57:476-487

DOI 10.1007/s00103-014-1939-y

๑) Springer-Verlag Berlin Heidelberg 2014
Bekanntmachung des Umweltbundesamtes

\section{Stoffmonographie Ochratoxin A}

\section{Stellungnahme der Kommission Human-Biomonitoring des Umweltbundesamtes}

\section{Einleitung}

Ochratoxin A (OTA) ist ein Mykotoxin und gehört damit zu einer strukturell extrem heterogenen Gruppe von Substanzen, die alle Metabolite des Sekundärstoffwechsels von Schimmelpilzen sind. OTA wurde erstmalig 1965 aus einer Kultur von Aspergillus ochraceus isoliert. Auch in anderen Aspergillen, z. B. Aspergillus carbonarius, findet sich OTA. Daneben produziert Penicillium verrucosum als einziger Vertreter der Schimmelpilzgattung Penicillium OTA.

Bei OTA handelt es sich um ein potentes Nephrotoxin und Nephrokanzerogen für Tier und Mensch. Seine Wirkungen werden mit der seit Langem bekannten endemischen Balkan-Nephropathie sowie der chronisch interstitiellen Nephropathie unbekannter Genese in Tunesien und den daraus resultierenden erhöhten Inzidenzen von Nierentumoren in Verbindung gebracht $[1,2]$.

\section{Physikalisch-chemische Eigenschaften}

OTA (• Abb. 1) ist ein bei Raumtemperatur farbloser, kristalliner Feststoff mit einem Schmelzpunkt bei $169^{\circ} \mathrm{C}$. - Tab. 1 beschreibt seine physikalisch-chemischen Eigenschaften. Die Salze von OTA sind gut wasserlöslich $[1,2]$.

\section{Vorkommen}

Für ein optimales Wachstum mit Mykotoxinproduktion bevorzugen AspergillusArten Temperaturen, wie sie in den Tropen und Subtropen vorherrschen (24$35^{\circ} \mathrm{C}$ ), während Penicillium verrucosum auch in kälterem Klima gedeiht (Temperaturoptimum $20^{\circ} \mathrm{C}$ ). Zucker dient dabei als Nährstoff $[1,2]$.

OTA findet sich weltweit als kaum vermeidbare Kontamination in vielen für den menschlichen Verzehr vorgesehenen Lebensmitteln und in Tierfutter. Es ist relativ hitzestabil, so waren noch $35 \%$ der Ausgangsmenge in einer Cerealienzubereitung nach 3-stündigem Autoklavieren nachweisbar [3].

OTA ist nachweisbar in zahlreichen pflanzlichen Produkten wie Getreide und daraus hergestellten Zubereitungen aller Art, Erdnüssen, Hülsenfrüchten, Reis, Kaffee, Kakao und seinen Zubereitungen, Gewürzen, Süßholz (Lakritze), Produkten aus Trauben (z. B. Saft, Trockenfrüchte, Wein) und Bier. OTA-Kontaminationen treten häufiger assoziiert mit einer Kontamination durch andere Mykotoxine auf $[4,5,6,7,8]$.

Das in Tierfutter vorhandene OTA wird von Nutztieren aufgenommen und findet sich nach deren Schlachtung im Fleisch und in Fleischprodukten. Schweinefleisch ist dabei am stärksten kontaminiert. Insbesondere Schlachtprodukte wie Blut, Niere und Leber weisen hohe Kontaminationen auf. Ältere Zusammenstellun- gen zum OTA-Gehalt von Nahrungsmitteln offerieren IARC [9] und WHO [10], aktuelle Daten präsentieren NTP [2] und Jørgensen [11], der die europäische Perspektive basierend auf den SCOOP-1- und SCOOP-2-Berichten (SCOOP: Scientific cooperation on questions relating to food) darstellt.

Nationale und übernationale Institutionen versuchen durch gesetzgeberische Maßnahmen und nachgeschaltete Kontrollen das Vorkommen von OTA in Nahrungsmitteln und Tierfutter zu regulieren. In der EU sind dazu entsprechende

Tab. 1 Physikalisch-chemische Eigen-

schaften von Ochratoxin A und Einstufungen der MAK-Kommission

\begin{tabular}{|c|c|}
\hline IUPAC & $\begin{array}{l}\text { 2-[(5-Chlor-8-hydroxy-3- } \\
\text { methyl-1-oxo-3,4-dihydro- } \\
\text { isochromen-7-carbonyl) } \\
\text { amino]-3-phenylpropan- } \\
\text { säure }\end{array}$ \\
\hline CAS-Nummer & $303-47-9$ \\
\hline Summenformel & $\mathrm{C}_{20} \mathrm{H}_{18} \mathrm{ClNO}_{6}$ \\
\hline $\begin{array}{l}\text { Molekularge- } \\
\text { wicht }(\mathrm{g} / \mathrm{mol})\end{array}$ & 403,8 \\
\hline Eigenschaften & $\begin{array}{l}\text { Farbloser, kristalliner Fest- } \\
\text { stoff bei RT }\end{array}$ \\
\hline Schmelzpunkt & $169^{\circ} \mathrm{C}$ \\
\hline Siedepunkt & k.A. \\
\hline Dampfdruck & $4,4 \times 10^{-16} \mathrm{hPa}$ bei $20^{\circ} \mathrm{C}$ \\
\hline Log $P_{\text {ow }}$ & 4,74 \\
\hline $\begin{array}{l}\text { Einstufungen } \\
\text { MAK-Kommis- } \\
\text { sion }\end{array}$ & $\begin{array}{l}\text { Krebserzeugende Wirkung } \\
\text { Kategorie } 2 \\
\text { Keimzellmutagene Wir- } \\
\text { kung Kategorie 3B }\end{array}$ \\
\hline
\end{tabular}




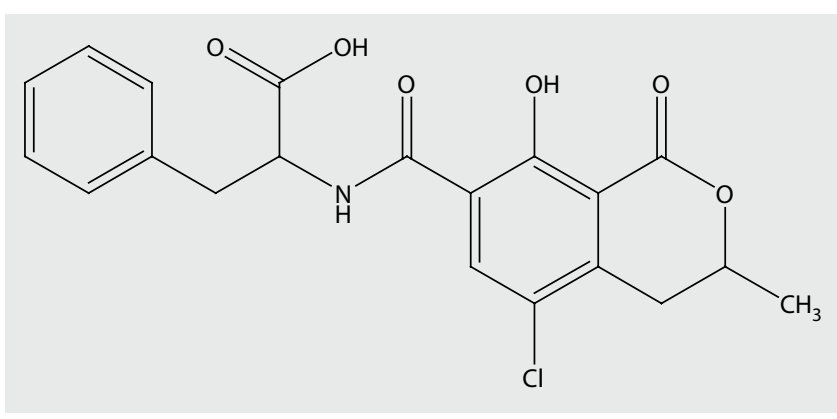

Abb. $1<$ Ochratoxin A

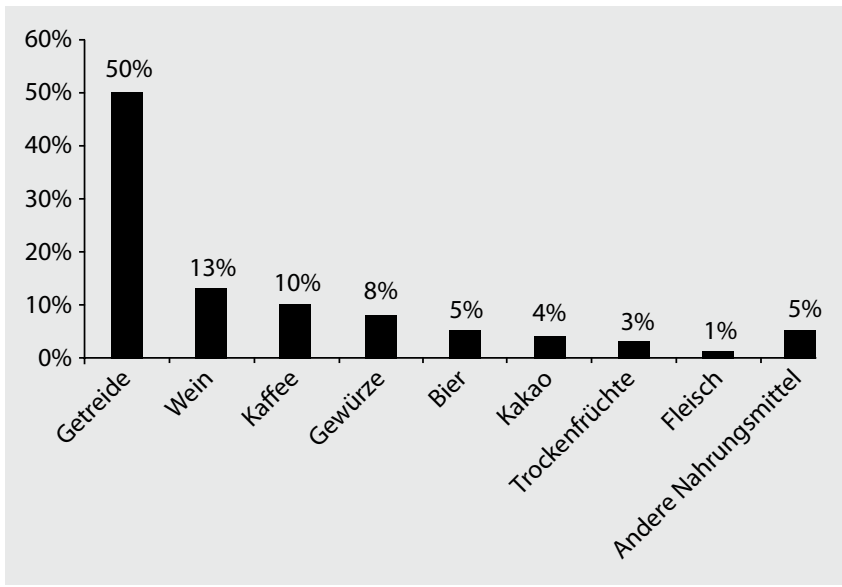

Abb. $2<$ Anteile der verschiedenen $\mathrm{Nah}$ rungsmittel an der durchschnittlichen OTA-Aufnahme mit der Nahrung. (Nach [20])

Höchstmengen in Nahrungsmitteln festgelegt worden [12, 13]. Als Beispiele seien hier die Höchstmengen für unverarbeitetes Getreide von $5 \mu \mathrm{g}$ OTA $/ \mathrm{kg}$ und für $\mathrm{Ge}$ treideerzeugnisse von $3 \mu \mathrm{g}$ OTA/kg sowie die Höchstmengen für Getreidebeikost und andere Beikost für Säuglinge und Kleinkinder oder eigens für Säuglinge bestimmte diätetische Lebensmittel für besondere medizinische Zwecke von jeweils $0,5 \mu \mathrm{g}$ OTA/ $\mathrm{kg}$ genannt. Für Tierfutter liegt bisher nur eine Empfehlung der Europäischen Kommission vor [14]. Darin wird eine Höchstmenge von $0,25 \mathrm{mg}$ OTA/kg für Getreide und Produkte auf Getreidebasis vorgeschlagen. Ergänzende und komplette Futtermittel dürfen für die Schweinezucht nur eine Höchstmenge von $0,05 \mathrm{mg}$ OTA $/ \mathrm{kg}$, für die Geflügelzucht eine Höchstmenge von 0,1 mg OTA/ $\mathrm{kg}$ aufweisen. Daneben eröffnet die Europäische Union die Möglichkeit, durch die Gabe von geeigneten Futtermittelzusätzen die Absorption von Mykotoxinen zu unterdrücken oder zu reduzieren, ihre Exkretion zu steigern oder ihre Wirkmechanismen zu verändern [15]. Diese eigentlich auf eine Qualitätssteigerung des auf dem Markt befindlichen Tierfutters abzielende gesetzgeberische Maßnahme birgt allerdings auch die Gefahr, dass durch einen missbräuchlichen Einsatz der Futtermittelzusätze eine Kontamination von Tierfutter kaschiert werden kann. Dies gilt insbesondere dann, wenn entsprechende Kontrollmaßnahmen fehlen. Eine aktuelle Zusammenstellung und kritische Würdigung der weltweiten regulatorischen Maßnahmen unter besonderer Berücksichtigung der EU geben Walker und Larsen [16] und Duarte et al. [17, 18].

\section{Exposition des Menschen}

Die Allgemeinbevölkerung nimmt OTA fast ausschließlich über die Nahrung auf, die inhalative Aufnahme wird als möglich, aber von nachgeordneter Bedeutung betrachtet [19].

\subsection{Aufnahme mit der Nahrung}

Bei der durchschnittlichen OTA-Aufnahme mit der Nahrung haben nach einer europaweiten Studie Getreide und Getreideprodukte mit 50\% den größten Anteil, gefolgt von Wein (13\%) und Kaffee (10\%) [20]. Abb. 2 gibt einen Überblick über die Anteile der verschiedenen Nahrungsmittel.
Bemerkenswert für Deutschland ist, dass in einer Studie über einen hohen Anteil (60\% aller untersuchten Proben) OTA-belasteter Getreideprodukte für Babys und Kleinkinder berichtet wird. Die mediane Konzentration lag hier bei $0,02 \mu \mathrm{g}$ OTA $/ \mathrm{kg}$, die maximale Konzentration bei $2,13 \mu \mathrm{g}$ OTA/kg (und damit über der von der EU erlaubten Höchstmenge von $0,5 \mu \mathrm{g} / \mathrm{kg}$ ). In einer italienischen Studie waren $17 \%$ aller Getreidezubereitungen für Babys mit OTA kontaminiert (maximale Konzentration: 0,74 $\mu \mathrm{g}$ OTA/kg), wobei Produkte aus biologischem Anbau stärker belastet waren als solche aus konventionellem Anbau mit integriertem Pestizideinsatz. Eine kanadische Untersuchung wies für $26 \%$ aller Proben von Getreideprodukten für Kleinkinder eine Kontamination mit OTA nach (maximale Konzentration: 2,4 $\mu$ g OTA/ kg) [19].

In Assoziationsstudien, die auf Biomonitoring und auf Ernährungsprotokollen (Food-Frequency-Recall) basieren, wurden die oben beschriebenen Nahrungsbeiträge bestätigt. So zeigen Di Giuseppe et al. [21], dass neben dem Verzehr von Getreideprodukten, dem Wein-, Bier- [22], Honig- und Marmeladenkonsum auch der Verzehr von Hammel- und Lammfleisch positiv mit der PlasmaOTA-Varianz assoziiert ist.

Basierend auf dem Vorkommen und dem Verzehr wird von der EU für Deutschland eine Aufnahme von 1,09 ng OTA/kg Körpergewicht/Tag für Erwachsene (>14 Jahre), von 1,82 ng OTA/kg Körpergewicht/Tag für Kinder ( $<14$ Jahre) und von 3,14 ng OTA/kg Körpergewicht/ Tag für weibliche Kleinkinder ( 4 bis 6 Jahre) geschätzt [20].

Die geschätzte tägliche Aufnahme liegt dabei - insbesondere für die Kleinkinder nahe der duldbaren täglichen Aufnahme („tolerable daily intake“ - TDI) von $5 \mathrm{ng}$ OTA/kg Körpergewicht/Tag wie sie von dem European Commission's Scientific Committee on Food (EC SCF) empfohlen wurde [23]. Dieser TDI-Wert wird aktuell unterstützt durch Studien einer kanadischen Arbeitsgruppe [24], die einen TDIWert von 4 ng OTA/kg Körpergewicht/ Tag präferiert. Hingegen schlägt das Joint FAO/WHO Expert Committee on Food Additives (JECFA) einen TDI-Wert 
von 14,28 ng OTA/kg Körpergewicht/ Tag vor [25], welcher gut mit dem TDIWert der European Food Safety Authority von 17,14 ng OTA/kg Körpergewicht/ Tag übereinstimmt $[26,27]$. Die wissenschaftlichen Hintergründe für die um den Faktor 3-4 unterschiedlichen TDI-Werte werden in Abschn. 5.3 vorgestellt.

\subsection{Andere Quellen}

OTA-haltige Konidien und Sporen von Schimmelpilzen können aufgewirbelt und weitergetragen werden, daher ist neben der Aufnahme mit der Nahrung eine inhalative Aufnahme von luftgetragenem OTA möglich. Hier sollten im Staub gemessene OTA-Konzentrationen Hinweise auf die Qualität und Quantität einer inhalativen Exposition geben. Obwohl dafür verschiedene Messverfahren entwickelt wurden, erfolgte noch keine Standardisierung; ein allgemein anerkanntes Messverfahren fehlt daher $[19,28]$.

An verschiedenen Arbeitsplätzen ist eine erhöhte luftgetragene OTA-Exposition zu erwarten. So gibt es einzelne Expositionsstudien aus der Landwirtschaft (z. B. Milchproduktion, Geflügelzucht) und der Lagerhaltung (z. B. Getreide, Kaffee, Kakaobohnen, Gewürze) [19, 29, 30]. Aufgrund der Defizite in der Standardisierung der Analytik und der schlechten Datenlage bei den Expositionsstudien sowie des kanzerogenen Potenzials von OTA gibt es bislang keine arbeitsplatzbezogenen Beurteilungswerte.

In der Umweltmedizin stellen neben direktem Schimmelpilzbefall in feuchten Gebäuden auch Heiz- und Ventilationssysteme sowie Klimaanlagen Quellen für eine mögliche luftgetragene OTA-Exposition dar [31]. Dies wird deutlich durch 2 Fallbeschreibungen, in denen in Staub bzw. der Luft vorliegende OTA-Belastungen mit Vergiftungssymptomen bei Menschen sowie Haustieren in Verbindung gebracht werden [19]. In einer Pilotstudie mit in 47 deutschen Haushalten gesammelten Hausstaubproben konnte in $~ 40 \%$ der Proben OTA nachgewiesen werden (Nachweisgrenze: 0,1 $\mu \mathrm{g} / \mathrm{kg}$ Feinstaub). In der Studie zeigte sich eine größtenteils sehr gute Übereinstimmung der Analysenergebnisse mit den telefonisch abgefragten baulichen Gegebenheiten bzw. vorhandenen sichtbaren Problemen mit Schimmelpilzen [28]. Auch für den umweltmedizinischen Bereich gibt es bislang keine Beurteilungswerte für die luftgetragene Exposition.

\section{Toxikologie}

Die toxischen Wirkungen von OTA werden seit Jahrzehnten untersucht und wurden von nationalen und internationalen Expertengremien wiederholt evaluiert. Zusammenfassende Darstellungen der toxischen Wirkungen und die aktuellen national und international anerkannten Bewertungen gibt die folgende Auswahl von Dokumenten und Übersichten wieder: IARC [9], WHO [10], DFG [1, 32], Pfohl-Leszkowicz und Manderville [33]. In diesen Quellen wird OTA als Krebs erzeugende Substanz eingestuft (DFG: Kategorie 2; IARC: Kategorie 2B). OTA muss daher, diesen Einstufungen folgend, die sich im Wesentlichen auf tierexperimentelle Befunde stützen, auch als Krebs erzeugend für den Menschen angesehen werden. Zusätzlich wird von der DFG für OTA der Verdacht auf eine mutagene Wirkung in Keimzellen abgeleitet und OTA in die Kategorie 3B eingestuft [1, 32]. Da keine hinreichenden Daten vorliegen, erfolgt durch die DFG keine Markierung mit „H“ (Gefahr der Hautresorption), „Sa“ (Gefahr der Sensibilisierung der Atemwege) oder „Sh“ (Gefahr der Sensibilisierung der Haut). Zwar zeigen jüngste In-vitro-Untersuchungen eine prinzipielle Penetration von OTA durch die menschliche Haut. Die auf der Basis des Modells kalkulierten täglichen dermalen Expositionen führten bei der Betrachtung zweier Umgebungen zu keinen signifikanten Gesundheitsrisiken (ein häusliches und 2 landwirtschaftliche Expositionsszenarien) [34].

\subsection{Toxische Wirkungen im Tierversuch}

Die Toxizität von OTA in Tierversuchen variiert erheblich in Abhängigkeit von der Tierart, dem Geschlecht und dem Aufnahmeweg in den Körper. Die wesentlichen toxischen Wirkungen umfassen eine ausgeprägte Nephrotoxizität, Kanzerogenität (Hauptzielorgan: Niere), Immuno- suppression bzw. Immunotoxizität und Teratogenität. Zur Einordnung der Toxizität nach oraler Aufnahme bei verschiedenen Tierarten seien als Beispiele die folgenden $\mathrm{LD}_{50}$-Werte (in $\mathrm{mg} / \mathrm{kg} \mathrm{KG}$ ) genannt: 0,2 für Hunde, 1 für Schweine, 20 30 für Ratten und 46-58 für Mäuse $[1,33]$.

OTA wirkt nephrotoxisch in Säugern und Vögeln, eine Ausnahme bilden hier ausgewachsene Wiederkäuer. Hunde und Schweine sind dabei deutlich empfindlicher als Nager, Geflügel zeigt neben der renalen Toxizität auch toxische Veränderungen der Leber [33]. Die auftretende Nephropathie ist gekennzeichnet durch Polyurie, Glukosurie, Proteinurie, Enzymurie, erniedrigte Osmolarität des Urins sowie eine Beeinträchtigung der tubulären Funktion [1]. Histopathologische Veränderungen manifestieren sich in den Epithelzellen der proximalen Tubuli. Dort finden sich in Untersuchungen bei Schweinen Schädigungen der Zellorganellen und der Zellkerne (z. B. Chromatinkondensation) und eine Reduktion in der Höhe und der Dichte des Bürstensaums. Bei fortschreitender Schädigung weisen die proximalen Tubuli ultrastrukturell Verdickungen der basalen tubulären Membranen und große Mengen von Kollagenfasern im Interstitium auf. Vergleicht man die beobachteten toxischen Wirkungen von OTA auf die Epithelzellen der proximalen Tubuli bei Schwein und Mensch so ergeben sich sehr gute Übereinstimmungen zu der bereits erwähnten endemischen Balkan-Nephropathie [33].

Die orale Gabe von OTA resultiert bei Ratten und Mäusen in der Bildung von Nierenzelladenomen und -karzinomen. Dabei erweisen sich in den Rattenversuchen die männlichen Ratten als empfindlicher als die weiblichen. Zusätzlich werden bei weiblichen Ratten nach der Gabe hoher OTA-Dosen Fibroadenome der Mamma festgestellt. Bei Mäusen werden neben renalen Neoplasien bei den männlichen Tieren auch hepatozelluläre Adenome und Karzinome bei beiden Geschlechtern gefunden $[1,2,33]$. Pfohl-Leszkowicz und Manderville [35] berichten 2012 über neue Studien, die eine Mutagenität von OTA in der Niere (s. auch Mantle et al. [36]) der männlichen Ratte belegen. 
OTA beeinflusst die Funktionen des Immunsystems in verschiedenen Tierspezies, z. B. in Ratten, Mäusen, Hühnern, Truthähnen, Hunden, Kaninchen und Schweinen. Immunotoxische Wirkungen von OTA umfassen das Schrumpfen von Organen des Immunsystems wie Thymus, Milz und Lymphknoten, Unterdrückung der Antikörperantwort, Veränderungen in der Anzahl und der Funktion verschiedener Immunzellen und eine Modulation der Zytokinproduktion [1, 33, 37].

OTA wirkt teratogen in Mäusen, Ratten, Hamstern, Hühnern und Kaninchen, aber nicht in Schweinen. Es kann in schwangeren Tieren über die Plazenta in die fötalen Gewebe gelangen, dort akkumulieren und Missbildungen, hauptsächlich im ZNS, hervorrufen [38]. Hsuuw et al. [39] weisen auf den Einfluss von OTA auf die Apoptosis im Blastozystenstadium der Entwicklung hin. Aktuelle Untersuchungen an Ratten belegen dabei, dass die Tierföten im Gestationsalter von 6 bis 7 Tagen besonders empfänglich für die teratogene Wirkung von OTA sind. Dabei reicht eine einzige orale Dosis von 2,75 mg/kg KG in schwangeren Wistar-Ratten aus, um einen Hydrozephalus, Mikrophthalmie, ein vergrößertes Nierenbecken und Nierenhypoplasie hervorzurufen. Neben der teratogenen Wirkung beeinflusst OTA die Fertilität von männlichen Wistar-Ratten durch eine Veränderung der Enzymaktivitäten im Hoden und eine Beeinträchtigung der Spermatogenese $[1,33,40]$.

\subsection{Toxische Wirkungen beim Menschen}

In den 1950er-Jahren wurde in deskriptiven Studien aus einigen Regionen Bulgariens, des damaligen Jugoslawiens und Rumäniens über eine chronische, letztendlich tödlich verlaufende Nierenerkrankung berichtet. Betroffen waren ausschließlich Personen aus landwirtschaftlichen Haushalten. Seit 1964 wird diese Krankheitsentität als endemische Balkan-Nephropathie („Balkan endemic nephropathy“ - BEN) bezeichnet [9]. Sie ist charakterisiert als eine bilaterale, nicht entzündliche chronische Nephropathie mit Tubuli-Degeneration, interstitieller Fibrose und im weiteren Krankheitsver- lauf auftretender Hyalinisierung der Nierenglomeruli. Es kommt zu einer starken Schrumpfung und einem Gewichtsverlust der Nieren. Nach den vorliegenden Untersuchungen erkrankten in den Endemiegebieten in Bulgarien und Kroatien mehr Frauen als Männer an BEN (Verhältnis Frauen:Männer: 1,61:1 bzw. 1,65:1). Aus Tunesien wird über ein Krankheitsbild mit analogen Symptomen berichtet; dieses wird als chronisch interstitielle Nephropathie unbekannter Ursache bezeichnet [41]. Vorhandene erhöhte Expositionen gegenüber OTA werden mit beiden Krankheitsentitäten in Verbindung gebracht $[1,33,41,42,43,44]$.

Das Vorliegen von BEN in einem bestimmten Gebiet scheint mit einer erhöhten Inzidenz und Mortalität von Tumoren des Harntrakts einherzugehen. In verschiedenen epidemiologischen Studien wird eine Assoziation zwischen einer erhöhten OTA-Exposition und dem verstärkten Auftreten von Harntrakttumoren hergestellt [1, 2, 33, 45, 46]. Zusätzlich zeigt eine Studie aus Bulgarien die bereits für BEN beschriebene höhere Empfindlichkeit des weiblichen Geschlechts für die Krebsentstehung auf [47]. Der beschriebene Zusammenhang zwischen OTA-Exposition und Tumorbildung im Harntrakt wird durch die Ergebnisse einer ägyptischen Studie unterstützt [48].

Hingegen weist die Bewertung vorliegender Studien durch die IARC [9] auf die methodischen Schwächen vieler epidemiologischer Studien hin, nämlich dass aus der regionalen Häufung der endemischen Balkan-Nephropathie und der gleichzeitig gesehenen höheren OTA-Exposition alleine nicht der Schluss gezogen werden kann, dass ein Zusammenhang zwischen einer Exposition gegenüber OTA und dem Auftreten von BEN und von Tumoren des Harntrakts gesichert sei („There is inadequate evidence in humans for the carcinogenicity of ochratoxin A“). Darüber hinaus liegen Untersuchungen vor, die eine (Ko-)Exposition gegenüber anderen Mykotoxinen wie Aristolochiasäure und Citrinin als (Mit-)Ursache für das Auftreten von BEN [6, 45, 49, 50] und für die beobachteten nephrotoxischen und -kanzerogenen Wirkungen nahelegen [33]. Entsprechende bevölkerungs- bezogene Risikoabschätzungen sind uneinheitlich [24, 51].

Die Gesamtsicht der epidemiologischen und der tierexperimentellen Daten legt jedoch eine kausale Beziehung zwischen einer hohen und andauernden OTA-Exposition und dem Auftreten von BEN und von Tumoren des Harntrakts nahe.

\section{Aufnahme, Verteilung und Metabolismus}

\subsection{Aufnahme und Verteilung}

Für OTA liegen toxikokinetische Untersuchungen in verschiedenen Tierspezies wie Schweinen, Ratten, Mäusen, Kaninchen, Hühnern, Wachteln, Fischen, Meerkatzen und Affen vor [52]. Für den Menschen wurde nach oraler Gabe von $395 \mathrm{ng}$ ${ }^{3} \mathrm{H}-\mathrm{OTA}$ an einen Freiwilligen eine 2-phasige Toxikokinetik beobachtet. In der 6-tägigen $\alpha$-Phase findet hauptsächlich eine Verteilung im Körper bei geringer Ausscheidung statt (Plasmahalbwertszeit: $20,13 \mathrm{~h}$ ), in der $\beta$-Phase ab dem 6 . Tag erfolgt die Elimination (Plasmahalbwertszeit: 35,55 Tage) [53].

OTA wird im Magen und im Gastrointestinaltrakt absorbiert und anschließend an Serumproteine gebunden. Es erfolgen ein Transport über das Pfortadersystem und die Verteilung in verschiedene Organe und Gewebe, wo es sich insbesondere in der Leber und den Nieren anreichert. OTA wird über die Nieren und die Faeces ausgeschieden; es wird aber auch über die Frauenmilch abgegeben.

Nach der Gabe von OTA in Ethanol auf nüchternen Magen an einen Freiwilligen fanden sich $8 \mathrm{~h}$ nach der Einnahme 93\% der verabreichten Dosis im Plasma und in den Erythrozyten [53]. Zum Vergleich: Schweine absorbieren $66 \%$, Ratten und Kaninchen 56\% und Hühner 40\% einer applizierten OTA-Dosis, allerdings gilt es dabei zu beachten, dass die Bioverfügbarkeit durch andere Nahrungsbestandteile, wie z. B. Flavonoide, moduliert werden kann [33]. Untersuchungen belegen, dass OTA im Blut ganz überwiegend $(99,9 \%)$ an Serumproteine, hauptsächlich Albumin, aber auch an andere Serummakromoleküle (z. B. nicht näher identifizierte mit einem Molekulargewicht von 
$\sim 20.000 \mathrm{u}$ ) gebunden vorliegt $[54,55]$. Der Anteil des freien OTA variiert speziesabhängig von $0,02 \%$ in Menschen und Ratten, $0,08 \%$ in Affen, $0,1 \%$ in Mäusen und Schweinen, $0,2 \%$ in Wachteln bis hin zu 22\% in Fischen [55]. In Erythrozyten sind nur Spuren von OTA nachweisbar [56]. Nach Fuchs und Hult [57] stellt das an Serumproteine gebundene OTA einen ,mobilen Speicher" dar, aus dem das Mykotoxin über einen langen Zeitraum schnell in verschiedene Gewebe des Körpers gelangen kann. Zusätzlich zeigen Untersuchungen an Nagern, dass OTA dem enterohepatischen Kreislauf und einer Reabsorption in den Nieren unterliegt. Dies kann die Verweildauer des aufgenommenen Mykotoxins in den Körpern der Versuchstiere verlängern [52]. Corcuera et al. [58] sehen keine Interaktion zwischen der Kinetik von OTA und Aflatoxin Bl bei gleichzeitiger Exposition.

Untersuchungen an verschiedenen Tierarten zeigen, dass die in den unterschiedlichen Geweben vorliegenden Mengen an OTA u. a. abhängig sind von der jeweiligen Spezies, den verabreichten Dosen und ihren Darreichungsformen (kristallin oder genuiner Bestandteil der Nahrung), der jeweiligen Nahrungszusammensetzung und dem Gesundheitszustand der Tiere [33]. Deutlich lässt sich in den Studien eine bevorzugte Anreicherung von OTA in den Organen Niere und Leber, gefolgt von Muskeln, Lunge und Herz belegen [52]. Ferner weisen Untersuchungen an Ratten auf eine geschlechtsspezifische Anreicherung von OTA hin. So fanden sich mit Ausnahme des Gehirns bei männlichen Tieren gröBere Mengen von OTA in der Leber, den Nieren und der Lunge als bei weiblichen Tieren [59]. OTA gelangt über die Plazenta in den Fötus: Die OTA-Spiegel in der humanen Plazenta und im fötalen Serum sind doppelt so hoch wie die mütterlichen Serumspiegel [60, 61].

OTA wird über die Niere, die Galle und die Faeces ausgeschieden sowie mit der Muttermilch abgegeben. Menschen und Affen scheiden OTA hauptsächlich über die Nieren aus, die Exkretion über die Galle ist der Hauptausscheidungsweg für Ratten, Mäuse, Wachteln und Fische [52]. Der Anteil des jeweiligen Exkretionswegs an der Gesamtausscheidung ist abhängig vom Aufnahmeweg, der Dosis, der Bindung an Serumproteine und der enterohepatischen Zirkulation [33]. Aufgrund der starken Proteinbindung erfolgt die glomeruläre Filtration nur in beschränktem Umfang, stattdessen gelangt OTA nach tubulärer Elimination in den Urin. Dabei gilt es zu beachten, dass OTA in allen Segmenten des Nephrons reabsorbiert wird, was seine Ausscheidung verzögert und zu einer Akkumulation in den Nieren führen kann $[56,62]$. Untersuchungen an Ratten belegen, dass die aus OTA gebildeten Metabolite wesentlich schneller über die Nieren und die Galle ausgeschieden werden als die Ausgangssubstanz [63]. Dabei geht die Ausscheidung in den Faeces zurück auf die vorangegangene biliäre Exkretion.

OTA findet sich in der Muttermilch verschiedener Säugetierarten wie Kaninchen, Ratten, Schweine, Rinder und beim Menschen [52].

\subsection{Metabolismus}

Es liegen zahlreiche Untersuchungsergebnisse zum Metabolismus von OTA in Versuchstieren, insbesondere in Ratten vor $[33,64]$. OTA wird in der Niere, der Leber und im Darm verstoffwechselt. Grenier und Applegate [65] fassen die Literatur zu direkten Wirkungen von Mykotoxinen, insbesondere auch OTA, im Darm zusammen. Ein Hauptmetabolit ist das Spaltprodukt Ochratoxin $\alpha$ (OTA $\alpha)$, dessen Bildung durch Carboxypeptidasen katalysiert werden kann. Die Bildung von OTA a gilt als Detoxifizierungsweg. 4-(R/S)-Hydroxy-Ochratoxin A [4-(R/ S)-OH-OTA] entsteht als wichtigster hydroxylierter Metabolit durch die Katalyse von Cytochromen P 450 (CYP 450) und trägt ebenfalls zur Entgiftung bei. Die Öffnung des Lactonrings im OTAMolekül (Metabolit OP-OTA) führt zu einer Verstärkung der Toxizität des Ausgangsmoleküls, dabei scheint die LactonCarbonyl-Gruppe im Isocumarinrest die biologische Reaktivität des Metaboliten zu bestimmen.

- Abb. 3 zeigt die in In-vitro-Versuchen mit menschlichen Zellen und subzellulären Fraktionen identifizierten Stoffwechselprodukte von OTA. Dabei finden sich 4-(R)-OH-OTA und 4-(S)-
OH-OTA als Metabolite in Inkubationen mit Humanlebermikrosomen und NADPH. Quantitativ überwog dabei das 4-(R)-OH-OTA gegenüber dem 4-(S)OH-OTA [66]. In einer anderen Untersuchung mit Humanlebermikrosomen und NADPH wurde 4-(R)-OH-OTA als einziges Produkt nachgewiesen [67]. In derselben Studie zeigte sich keine Metabolisierung von OTA in Anwesenheit von humanen Nierenmikrosomen; eine Glutathionkonjugation war ebenfalls nicht nachweisbar. Rekombinante humane Cytochrome P 450 1A1 und 3A4 katalysieren die Bildung von 4-(R)-OH-OTA aus OTA.

In Inkubationen mit menschlichen primären Hepatozyten wird OTA nur schwach verstoffwechselt. Neben geringen Mengen von 4-(R/S)-OH-OTA (Isomere nicht differenziert) konnte ein Hexosederivat identifiziert werden. Die Strukturen von 4 weiteren Metaboliten wurden nicht aufgeklärt [68].

Des Weiteren zeigen In-vitro-Untersuchungen an humanen epithelialen Lungenzellen die Bildung der Metabolite OTA $\alpha, 4-(\mathrm{R})$-OH-OTA und 4-(S)-OHOTA sowie eines weiteren, nicht näher charakterisierten Stoffwechselprodukts [69].

\subsection{Mechanismen der Tumorentstehung}

Für OTA werden aktuell 3 Mechanismen der renalen Tumorentstehung ["modes of action" (MOA)] kontrovers diskutiert.

Ein klassischer Ansatz erklärt die Tumorentstehung durch die kovalente Bindung von OTA-Metaboliten an die DNA. So erlaubt die chemische Struktur von OTA das Auftreten von Phenol- und Arylradikalen sowie eines elektrophilen Chinons. In vitro und in vivo lassen sich mittels des ${ }^{32} \mathrm{P}$-Postlabeling-Verfahrens zahlreiche DNA-Addukte nachweisen [35]. Kritisch anzumerken ist jedoch, dass Versuche mit radioaktiv markiertem OTA bisher keine Bindung an die DNA belegen konnten, sodass die im ${ }^{32} \mathrm{P}$-Postlabeling-Verfahren beobachteten Addukte möglicherweise kein OTA oder Teile des OTA-Moleküls enthalten. Auch modernste u. a. auf Massenspektrometrie basierende Verfahren mit Detektionsgrenzen von $<2,7$ Addukte $/ 10^{9}$ DNA-Basen 


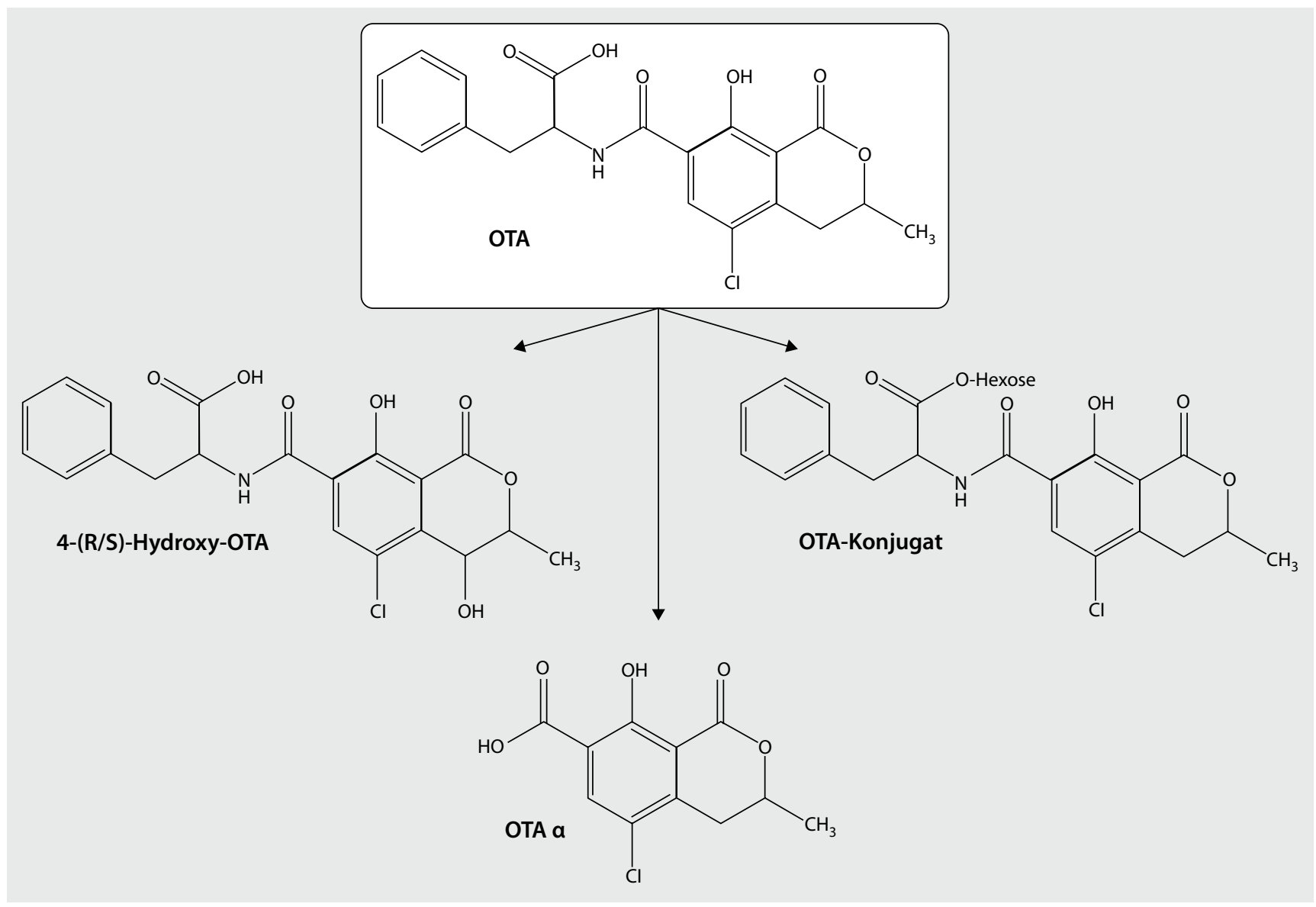

Abb. $3 \Delta$ Stoffwechselprodukte von OTA (in In-vitro-Versuchen mit menschlichen Zellen und subzellulären Fraktionen identifiziert)

konnten kein radioaktiv markiertes OTA in Rattennieren-DNA nachweisen [70, 71].

Als zweiter möglicher Mechanismus wird oxidativer Stress induziert durch OTA angesehen. Dabei fördert OTA die Bildung von reaktiven Sauerstoffspezies ["reactive oxygen species" (ROS)]. Diese führen zu oxidativen DNA-Schäden, welche indirekt durch die Formamido-Pyrimidin-DNA-Glycosylase-Variante des Comet-Assay nachgewiesen werden können. Die entstandenen Schäden können durch erhöhtes renales Zellwachstum in permanente Mutationen überführt werden, verbunden mit der klonalen Expansion der initiierten Zellen [35, 70]. Dabei gilt es allerdings zu beachten, dass dieser auf oxidativer DNA-Schädigung und anhaltender Zytotoxizität basierende $\mathrm{Me}$ chanismus nur schwierig vereinbar ist mit den beobachteten pathologischen Veränderungen in den Nieren wie frühes Auftreten und Häufigkeit von Karyomegalie und Polyploidie von Zellen sowie mit der einzigartigen Aggressivität der Tumoren [70]. Hinzu kommt, dass oxidative DNASchäden nicht nur in den Nieren von Ratten beobachtet wurden, sondern in gleichem Ausmaß auch in den Lebern von OTA-behandelten Tieren auftraten [72, 73]. Daher ist ein Beitrag dieses Mechanismus zur Tumorentstehung nicht auszuschließen; es dürfte sich aber nicht um den ausschlaggebenden Mechanismus handeln.

In den letzten Jahren wurde ein neuer indirekter Mechanismus für die Tumorentstehung durch OTA vorgeschlagen $[70,71]$. Beginnend mit der renalen Aufnahme von OTA in den proximalen $\mathrm{Tu}$ bulus kommt es zur Hemmung von Histon-Acetyltransferasen (HAT). Dies führt $\mathrm{zu}$ einer Unterbrechung der Zellteilung in der G2/M-Phase mit darauffolgendem Zelltod von betroffenen Zellen neben der gleichzeitigen Bildung von genetisch instabilen polyploiden Zellen. Der Zellverlust stimuliert die weitere Zellprolifera- tion im Gewebe, wobei auch polyploide Zellen wieder in den Zellzyklus eintreten können. Die Folge ist eine fortschreitende chromosomale Instabilität in zahlreichen Zellen, die zur Aneuploidie und Krebs führen kann. Obwohl viele Ergebnisse von Untersuchungen zur Krebsentstehung durch OTA mit dem vorgeschlagenen Mechanismus sehr gut vereinbar sind, weisen die Autoren auf Schwächen ihres Vorschlags hin [71]. So wurde die Inhibition der HAT durch OTA bisher überwiegend nur in vitro gezeigt, einzelne OTA-suszeptible HAT müssen noch identifiziert werden, und Details zu den postulierten Mechanismen und Stoffwechselwegen von der Inhibition bis zur Krebsentstehung sollten experimentell weiter abgesichert werden. Schließlich ist die Geschlechts- und Speziesspezifität der vorgeschlagenen Abfolge von Schritten von der OTA-Aufnahme bis zur Tumorentstehung als ein wesentlicher Diskussionspunkt der anhaltenden wissen- 
schaftlichen Auseinandersetzung zu klären [35].

Je nach Sichtweise haben die vorgestellten Mechanismen der renalen Tumorentstehung durch OTA unmittelbaren Einfluss auf die Risikobewertung der Substanz.

Da gemäß wissenschaftlicher Evaluation durch die EFSA $[26,27]$ keine OTA-spezifischen DNA-Addukte nachweisbar sind, wendet sie ein Schwellenwertkonzept zur Risikobewertung von OTA an. Ausgehend von einem „lowest observed adverse effect level“" (LOAEL) von $8 \mu \mathrm{g}$ OTA/kg KG/Tag als Frühmarker der renalen Toxizität im Schwein, der sensitivsten Tierspezies, wird ein Unsicherheitsfaktor von 450 (Extrapolation vom Tier zum Menschen, Intraspeziesvariabilität] angewandt und ein TDI-Wert von 17,14 ng OTA/kg Körpergewicht/Tag abgeleitet. Dieser TDI-Wert befindet sich in guter Übereinstimmung mit dem Vorschlag des Joint FAO/WHO Expert Committee on Food Additives (JECFA) von 14, 28 ng OTA/kg Körpergewicht/Tag [25].

Hingegen schließt Health Canada eine direkte gentoxische Wirkung von OTA nicht aus, schlägt daher für OTA eine Regulierung als Karzinogen ohne Schwellenwert vor und empfiehlt einen TDI-Wert von 4 ng OTA/kg Körpergewicht/Tag [24].

\section{Human-Biomonitoring}

\subsection{Auswahl der Parameter}

OTA kann als unveränderte Substanz im Plasma/Serum, Urin und Muttermilch nachgewiesen werden $[74,75]$.

Dabei gilt das Human-Biomonitoring im Serum/Plasma derzeit als Parameter der Wahl, um eine über mehrere Wochen vorliegende Exposition des Menschen erfassen zu können. Aktuell erhobene Individualwerte sollten vorsichtig bewertet werden (s. Abschn. 6.3), hingegen ist der Parameter sehr gut geeignet, um die innere Exposition von Bevölkerungsgruppen zu erfassen, insbesondere in prospektiven Studien [75].

Dem Nachweis von OTA im Urin wird in der Literatur das Potenzial eingeräumt, eine akute hohe Exposition besser abzubilden. Nachteilig sind hier die im Vergleich zum Serum/Plasma sehr viel nied- rigeren OTA-Konzentrationen, die besondere Herausforderungen an ihre analytisch verlässliche Erfassung stellen. Weitere Studien insbesondere zur Eliminationskinetik erscheinen nach übereinstimmender Expertenmeinung erforderlich, um OTA im Urin als Marker der inneren Exposition fest zu etablieren. $\mathrm{Zu}$ sätzlich könnten bisher kaum untersuchte OTA-Metabolite im Urin eine Alternative darstellen [74, 75, 76].

Verschiedene Studien belegen das Vorkommen von OTA in Muttermilch $[74,75]$. Bei parallelen Bestimmungen von OTA im Serum bzw. Blut und in der Muttermilch in Deutschland und Schweden zeigte es sich, dass in den Muttermilchproben keine oder viel geringere OTA-Konzentrationen nachweisbar waren als in den OTA-positiven Blutproben. Dies deckt sich mit Untersuchungen von Breitholtz-Emanuelsson et al. [77], die um den Faktor 10 geringere OTA-Konzentrationen in Muttermilch im Vergleich zum Plasma fanden. Kürzlich wiesen Munoz et al. [78] in mehr als der Hälfte von 90 Muttermilchproben aus Nordrhein-Westfalen und Niedersachsen eine OTA-Kontamination nach (Nachweisgrenze: 10 ng OTA/l, Bestimmungsgrenze: 30 ng OTA/l), der Gesamtmittelwert aller Proben der Dortmunder Gruppe beträgt 24,4 ng OTA/l (Standardabweichung: 21,1 ng OTA/1; n=30), demgegenüber der des niedersächsischen Kollektivs 14,4 ng OTA/l (Standardabweichung: 15,1 ng OTA/l; n=60). Die täglichen Aufnahmen von OTA durch den gestillten Säugling im Dortmunder Kollektiv wurden zu 0,3-10,3 ng und in der niedersächsischen Gruppe zu 0,3-11,7 ng OTA ermittelt. Damit lägen die täglichen Aufnahmen von OTA durch Säuglinge oberhalb des TDI-Wertes für $13 \mathrm{der}$ Dortmunder und 13 der niedersächsischen Muttermilchproben ( $29 \%$ aller Proben), wenn sie ausschließlich gestillt würden. Vor diesem Hintergrund empfehlen die Autoren verstärkte Anstrengungen zur Regulation der OTA-Gehalte in Lebensmitteln.

\subsection{Analytik}

Die meisten Analysenverfahren zum Nachweis von OTA aus menschlichem
Plasma/Serum nutzen zur Probenaufbereitung eine saure Extraktion in Anwesenheit von Magnesiumchlorid mit chlorierten Lösungsmitteln wie Chloroform und Dichlormethan. Daneben kommen auch die Festphasenextraktion und die Immunoaffinitätschromatographie zum Einsatz. Nach dem Abdampfen des Lösungsmittels und Aufnahme in der mobilen Phase erfolgt eine flüssigkeitschromatographische Abtrennung mit anschließender Fluoreszenzdetektion $\left(\lambda_{\text {ex }}: 330\right.$ 340 ; $\lambda_{\mathrm{em}}: 420-470 \mathrm{~nm}$ ) [74]. Ein auf den genannten Prinzipien beruhendes und bis in den Bereich der umweltbedingten Hintergrundbelastung messendes Standardverfahren zur Bestimmung von OTA wurde kürzlich von der Senatskommission zur Prüfung gesundheitsschädlicher Arbeitsstoffe der DFG veröffentlicht [79]. Alternative Analysenmethoden sind der Radioimmunoassay (RIA) oder Enzymimmunoassays (EIA) [80]. Dabei zeigt der aktuelle Vergleich eines HPLC-Verfahrens mit einem OTA-EIA eine zufriedenstellende Korrelation $\left(\mathrm{r}^{2}=0,768\right)$ der mit beiden Verfahren gemessenen Werte [81]. Für die Bestimmung von OTA aus kleinvolumigen Serumproben, wie sie bei Untersuchungen von Kindern gewonnen werden, wurde eine Messmethode, basierend auf einer Kapillarzonenelektrophorese mit laserinduzierter Fluoreszenzdetektion, entwickelt [82].

In der Literatur finden sich für die Analysenverfahren in älteren Untersuchungen Detektionsgrenzen von 1-2 ng OTA/g Serum und entsprechend eine geringere Anzahl von Proben, in denen OTA nachweisbar ist. In jüngeren Studien liegen die Detektionsgrenzen der Nachweisverfahren typischerweise im Bereich von 0,02-0,1 ng OTA/ml Serum oder Plasma [74].

\subsection{Einflussfaktoren}

Die Einflüsse verschiedener Faktoren auf den humanen Serum/Plasmaspiegel von OTA wie Erkrankungen der Nieren und des Urogenitaltrakts, intraindividuelle Schwankungen im zeitlichen Verlauf, Alter, Geschlecht, die Jahreszeit (z. B. [83]) und der Aufenthalt in einer bestimmten geografischen Region sind untersucht worden. 
Im Hinblick auf Erkrankungen der Nieren und des Urogenitaltrakts finden sich in den meisten Studien signifikant erhöhte OTA-Serum- oder Plasmaspiegel bei den erkrankten im Vergleich zu den nicht erkrankten Personen [74, 75], wobei OTA nicht das auslösende Agens der beobachteten Erkrankungen sein muss. Eine geringere Ausscheidung als Folge der bestehenden Erkrankung scheint für die erhöhten Blutspiegel mit verantwortlich $\mathrm{zu}$ sein.

Intraindividuelle Unterschiede im zeitlichen Verlauf bei wiederholter Bestimmung aus dem Serum/Plasma derselben Person wurden in zahlreichen Untersuchungen beschrieben [74, 75]. Dabei ließen sich extreme Schwankungen der OTA-Spiegel um den Faktor 100 belegen [84], typisch aber scheinen Schwankungen um den Faktor 1-10 zu sein [53, 61, 81, 85]. Aufgrund dieser Variabilität ist eine wiederholte Bestimmung des OTASerum/Plasmaspiegels in zeitlichem Abstand zu empfehlen, um eine mittlere innere Exposition des Individuums zu ermitteln $[81,86]$.

Alter und Geschlecht haben keinen nennenswerten Einfluss auf die Modulation der Serum/Plasmaspiegel von OTA. Nahezu alle in der Literatur vorliegenden Studien können keinen statistisch signifikanten Zusammenhang der genannten Größen mit den gemessenen OTASpiegeln feststellen $[74,75]$. Es gibt keine systematischen Untersuchungen von OTA-Spiegeln bei Kindern, einzelne Studien bei Neugeborenen (Nabelschnurblut, fötales Serum, Plazenta) weisen auf höhere OTA-Spiegel im Vergleich zu den bei den Müttern gemessenen hin [74].

Verschiedene Untersuchungen belegen den Einfluss der Jahreszeit auf den Serum/ Plasmaspiegel der untersuchten Personen. Übereinstimmend wird über erhöhte OTA-Spiegel im Sommer im Vergleich zum Winter berichtet [74, 75]. Als eine wesentliche Ursache für die beobachteten Unterschiede wird in einer Studie landesspezifisches saisonabhängiges Ess- und Trinkverhalten genannt [87].

In der Literatur finden sich zahlreiche Beispiele für Unterschiede in den OTA-Serum/Plasmaspiegeln in Abhängigkeit vom Aufenthalt eines Individuums in einer bestimmten geografischen
Region [88, 89]. Verantwortlich hierfür werden Unterschiede in den klimatischen Bedingungen und in der regionalen Ernährungsweise gemacht [74, 75]. Für Deutschland wurden signifikante regionale Abweichungen beschrieben: Hier reichen die mittleren OTA-Serumspiegel von $0,17 \mathrm{ng}$ OTA/ml für München bis $0,34 \mathrm{ng}$ OTA/ml für Jena $[90,91]$.

\subsection{Beziehung zwischen dem OTA-Serum/Plasmaspiegel und der Exposition: die Klaasen-Gleichung}

Mithilfe der Klaasen-Gleichung kann die kontinuierliche Aufnahme von OTA mit der Nahrung des Menschen aus dem gemessenen Serum/Plasmaspiegel abgeschätzt werden [53, 55, 88, 92, 93]. In der Gleichung werden die Serum/Plasmakonzentration, die Plasma-Clearance (unter ausschließlicher Berücksichtigung der renalen Filtration) und die Bioverfügbarkeit miteinander verknüpft, das Alter und das Geschlecht werden in der vereinfachten Berechnung nicht berücksichtigt:

$$
\mathrm{K}_{0}=0,99 \cdot \mathrm{C}_{\mathrm{P}} / 0,5=1,97 \cdot \mathrm{C}_{\mathrm{P}}
$$

bzw.

$$
\mathrm{K}_{0}=0,67 \cdot \mathrm{C}_{\mathrm{P}} / 0,5=1,34 \cdot \mathrm{C}_{\mathrm{P}}
$$

Dabei steht $\mathrm{K}_{0}$ für die kontinuierliche Aufnahme von OTA mit der Nahrung (ng OTA/kg KG/Tag), 0,99 bzw. 0,67 für die renale Filtrationsrate (ml/kg KG/Tag), 0,5 für den Bioverfügbarkeitskoeffizienten von OTA und $\mathrm{C}_{\mathrm{P}}$ für die Serum/Plasmakonzentration (ng/ml). Die Filtrationsrate $0,67 \mathrm{ml} / \mathrm{kg} \mathrm{KG/Tag}$ geht zurück auf tierexperimentelle Studien von Hagelberg et al. [55], die Filtrationsrate 0,99 ml/kg KG/ Tag auf eine Humanstudie, in der ein Freiwilliger Tritium-markiertes OTA zu sich nahm $[92,93]$. Neuere Untersuchungen verwenden für ihre Berechnungen die auf der Humanstudie basierende Filtrationsrate $[20,81]$. In verschiedenen epidemiologischen Studien wurden die aus den Serum/Plasmaspiegeln abgeschätzten täglichen OTA-Aufnahmen mit den aus Vorkommen und Verzehr abgeschätzten täglichen OTA-Aufnahmen verglichen.

Für 6 europäische Länder - Deutschland, Italien, Norwegen, Spanien, Schwe- den und Großbritannien - ergaben sich durchschnittliche tägliche OTA-Aufnahmen von $0,35-2,34 \mathrm{ng} / \mathrm{kg} \mathrm{KG} / \mathrm{Tag}$ ausgehend von durchschnittlichen Serum/ Plasmaspiegeln von $0,18-1,19$ ng OTA/ $\mathrm{ml}$ Serum/Plasma (angewandter Faktor der Klaasen-Gleichung: 1,97). Dabei lagen die aus Vorkommen und Verzehr abgeschätzten täglichen OTA-Aufnahmen in Deutschland (1,09 ng OTA/kg KG/Tag, Erwachsene), Norwegen (0,97 ng OTA/ kg KG/Tag, Verbraucher), Schweden (1,44 ng OTA/kg KG/Tag, erwachsene Verbraucher) und Italien (3,52 ng OTA/ kg KG/Tag, Verbraucher) höher als die aus den durchschnittlichen Serum/Plasmaspiegeln berechneten, die aus Vorkommen und Verzehr abgeschätzten täglichen OTA-Aufnahmen in Großbritannien (1,38 ng OTA/kg KG/Tag, erwachsene Verbraucher) und Spanien (1,18 ng OTA/kg KG/Tag) lagen niedriger als die aus den durchschnittlichen Serum/Plasmaspiegeln berechneten [20]. Eine in Großbritannien durchgeführte Duplikat-Nahrungsstudie zeigte einen erheblichen Unterschied zwischen der durchschnittlichen Aufnahme von OTA mit der Nahrung (0,94 ng OTA/kg KG/Tag) und der aus den durchschnittlichen OTA-Serum/Plasmaspiegeln berechneten täglichen Aufnahme (2,15 ng OTA/kg KG/Tag, angewandter Faktor der Klaasen-Gleichung: 1,97) [86]. Weitere Studien $[94,95,96]$ beschreiben ähnliche Unterschiede zwischen ihren einerseits auf Konsumentenbefragungen und analytischen Daten aus der Literatur basierenden täglichen Aufnahmeberechnungen und den aus den durchschnittlichen OTA-Serum/Plasmaspiegeln berechneten täglichen Aufnahmen andererseits. Abweichend davon sehen Märtlbauer et al. [81] eine gute Übereinstimmung zwischen den mit beiden Methoden generierten Datensätzen.

Für diese nicht eindeutige Korrelation werden zum einen vereinfachende Annahmen bei der Aufstellung der Klaasen-Gleichung (z. B. die ausschließliche Berücksichtigung der renalen Filtration), zum anderen methodische Schwächen bei der Erfassung der Vorkommens- und Verzehrdaten verantwortlich gemacht [75].

Trotz dieser Diskrepanzen wird die Abschätzung der täglichen Aufnahme 
Tab. 2 Statistische Angaben zur Ochratoxin-A-Konzentration im Serum ( $\mathrm{ng} / \mathrm{ml}$ ) von Probanden ausgewählter Studienorte nach Rosner et al. [91] sortiert nach Fallzahlen

\begin{tabular}{lllllll}
\hline Ort & $\mathbf{N}$ & $\mathbf{n}(\mathbf{x}>$ LOD $)$ & Mittelwert & Median & 90\%-Quantil & Maximum \\
\hline Jena & 211 & 208 & 0,34 & 0,27 & 0,58 & 1,63 \\
\hline Karlsruhe & 119 & 118 & 0,06 & 0,21 & 0,37 & 2,03 \\
\hline Detmold & 97 & 97 & 0,22 & 0,21 & 0,37 & 0,55 \\
\hline $\begin{array}{l}\text { Infratest } \\
\text { (Deutschland) }\end{array}$ & 83 & 83 & 0,24 & 0,23 & 0,37 & 0,59 \\
\hline Trier & 80 & 80 & 0,23 & 0,21 & 0,39 & 0,57 \\
\hline Kulmbach & 74 & 74 & 0,26 & 0,21 & 0,48 & 0,91 \\
\hline Kiel & 54 & 50 & 0,33 & 0,31 & 0,54 & 0,94 \\
\hline $\begin{array}{l}\text { Jena/Kiel/Kulm- } \\
\text { bach II }\end{array}$ & 52 & 49 & 0,29 & 0,26 & 0,47 & 1,00 \\
\hline Berlin & 50 & 46 & 0,20 & 0,16 & 0,35 & 0,49 \\
\hline Erlangen/Nürnberg & 50 & 48 & 0,28 & 0,27 & 0,43 & 0,50 \\
\hline München & 18 & 18 & 0,17 & 0,14 & 0,34 & 0,40 \\
\hline
\end{tabular}

von OTA, basierend auf durchschnittlichen Serum/Plasmaspiegeln, in zahlreichen Studien angewandt [74], da dort mithilfe des HBM auf einfache Weise ein erster Überblick zur OTA-Exposition eines Kollektivs zu gewinnen ist.

\section{Hintergrundbelastung der Bevölkerung und Referenzwert}

Von der Kommission wird die Studie von Rosner et al. [91] als prinzipiell geeignet betrachtet, die Hintergrundbelastung der deutschen Aufenthaltsbevölkerung zu beschreiben. Die Daten dieser Untersuchung bildeten auch zum Teil die Grundlage der deutschen Populationsdaten für die Beschreibung der OTA-Exposition in den Mitgliedstaaten auf europäischer Ebene [20]. Arbeiten von Märtlbauer et al. [81] zum zeitlichen Verlauf der OTA-Exposition über einen Zeitraum von 7 Jahren in einem kleinen Kollektiv in Deutschland belegen die Konstanz der Exposition hierzulande, sodass auch die vorliegenden älteren Daten für die Einschätzung der aktuellen OTA-Belastung in Deutschland genutzt werden können.

Rosner et al. [91] fanden bei 927 Untersuchten aus 8 Städten in Deutschland (Karlsruhe, Jena, Kiel, Trier, Kulmbach, Detmold, Berlin, München) und einer über ganz Deutschland gestreuten zufälligen Auswahl von Personen (83 Teilnehmer/innen) Werte zwischen $<0,06$ und 2,03 ng OTA/ml Serum. Der Mittelwert lag bei $0,27 \mathrm{ng}$ OTA $/ \mathrm{ml}$ und das 90 . Perzentil bei $0,45 \mathrm{ng}$ OTA/ml. Dies befindet sich in guter Übereinstimmung mit den deutschen Populationsdaten der europäischen Studie (Mittelwert: 0,23 ng OTA/ml Serum; $\mathrm{n}=1732$ ) [20]. Märtlbauer et al. [81] geben nach der Auswertung von $52 \mathrm{Stu}-$ dien in verschiedenen Ländern einen weltweiten OTA-Mittelwert (,mean of means") von $0,68 \mathrm{ng} / \mathrm{ml}$ Serum (niedrigster Mittelwert: 0,068 ng OTA/ml, höchster Mittelwert: 2,8 ng OTA $/ \mathrm{ml}$ ) an.

Der Referenzwert ist definiert als das 95. Perzentil der Messwerte der Stoffkonzentration in dem entsprechenden Körpermedium der jeweiligen Referenzpopulation. Er wird aus dem 95\%-Konfidenzintervall des 95. Populationsperzentils abgeleitet und möglichst als gerundeter Zahlenwert angegeben [97, 98].

Aus der oben genannten Datenbeschreibung $[90,91]$ wurden auf der Basis der berichteten deskriptiven Kennwerte (Minimum, Maximum, arithmetischer Mittelwert, Median, 90. Perzentil) die Verteilungsparameter einer zugrunde liegenden Log-Normalverteilung geschätzt. Nur etwa $1 \%$ der Daten lagen unter der Nachweisgrenze. Die Einzeldaten lagen der Kommission HumanBiomonitoring des Umweltbundesamtes nicht vor. Die statistische Sekundärdatenanalyse erfolgte sowohl für die berichteten Untersuchungsstandorte und Teilstichproben getrennt wie für die zusammengefasste Gesamtstichprobe ( $\mathrm{n}=888)$. Unter Nutzung der statistischen Angaben der Originalarbeit von Rosner et al. [91]
(Kennziffern: n, Min, Max, Mittelwert, Median, 90\%-Quantile, Prozent der Werte $>$ LOD, $\bullet$ Tab. 2) wurde für die Einzelorte und für die gewichtete Gesamtverteilung jeweils eine logarithmische Normalverteilung (Quantilregression der logarithmisch transformierten Werte) an die Daten angepasst.

Für die Verteilung der fallzahlgewichtet zusammengeführten Angaben der Einzelstudien wurde ein 95\%-Referenzquantil von $\sim 0,65 \mathrm{ng} \mathrm{OTA} / \mathrm{ml} \mathrm{Se}-$ rum geschätzt, dessen untere $95 \%$-Konfidenzintervallgrenze bei $\sim 0,50 \mathrm{ng}$ OTA/ $\mathrm{ml}$ Serum liegt. Die Schätzungen zeigen eine deutliche Variation über die Untersuchungsorte. Auf der Grundlage einer Schätzung der Verteilungsparameter über die berichteten Mediane, Mittelwerte und 90\%-Quantile würde sich ein geringfügig höherer Referenzwert ergeben.

Die Unsicherheit, die aus der Heterogenität der Parameterschätzungen (insbesondere aus der Datenlage und Methodik der Schätzung der geometrischen Standardabweichung aus Median/90. Perzentil, Median/Mittelwert) resultiert, wurde in der Ableitung des Referenzwertes berücksichtigt. Unsicherheiten bezüglich der Aussagekraft der vorliegenden Daten resultieren insbesondere aus der nicht repräsentativen Stichprobenzusammensetzung (Blutspender) und der Selektion der Probanden. Die von Rosner et al. [91] berichtete Datenlage für Kinder und Jugendliche wurde als zu schwach für eine gesonderte Referenzwertableitung eingestuft $(n=39)$.

Anhand der vorliegenden Studien wird folgender Referenzwert für Ochratoxin A abgeleitet:

0,5 $\mu \mathrm{g}$ OTA/l Serum für Erwachsene.

Aus dem Referenzwert lässt sich mithilfe der Klaasen-Gleichung eine mittlere tägliche Aufnahme von 0,99 ng OTA/kg KG/ Tag (angewandter Faktor der KlaasenGleichung: 1,97) abschätzen. Damit liegt das Aufnahmekorrelat des Referenzwerts Faktor 4 unter dem von Health Kanada bzw. Faktor 17 unter dem von der EFSA empfohlenen TDI-Wert. Gleichwohl sind mit Blick auf die Krebs erzeugende Wirkung von OTA im Tierversuch alle Maß- 
nahmen zur weiteren Reduktion des Mykotoxins in der Nahrung zu begrüßen.

\section{Zur Frage von HBM-Werten}

Die Kommission sieht vor dem Hintergrund des wissenschaftlichen Kenntnisstandes davon ab, toxikologisch begründete HBM-Werte für Ochratoxin A abzuleiten. Der wesentliche Grund liegt darin, dass für die Substanz(gruppe) OTA angenommen werden muss, dass sie beim Menschen Krebs erzeugend wirkt.

\section{Anmerkung}

Diese Stellungnahme wurde von Herrn PD Dr. Michael Müller (Göttingen) und Herrn Dr. Michael Schümann (Hamburg) erstellt und im Juni 2013 von der Kommission Human-Biomonitoring verabschiedet. Die redaktionelle Bearbeitung im UBA erfolgte durch Frau Angela Lehmann und Frau Petra Apel.

\section{Literatur}

1. Greim H (Hrsg) (2003) Ochratoxin A. Gesundheitsschädliche Arbeitsstoffe: Toxikologisch-arbeitsmedizinische Begründung von MAK-Werten. 37. Lieferung. Wiley-VCH, Weinheim. http://onlinelibrary.wiley.com/doi/10.1002/3527600418. mb30347d0037/pdf

2. NTP (National Toxicology Program, U.S. Department of Health and Human Services) (2011) 12th Report on Carcinogens. http://ntp.niehs.nih.gov/ ntp/roc/twelfth/roc12.pdf, http://ntp.niehs.nih. gov/

3. IARC (1976) Ochratoxin A. IARC monographs on the evaluation of the carcinogenic risk of chemicals to man: some naturally occurring substances. 10:191-197. http://monographs.iarc.fr/ENG/Monographs/vol1-42/mono10.pdf

4. Domijan AM, Peraica M, Cvjetković B et al (2005) Mould contamination and co-occurrence of mycotoxins in maize grain in Croatia. Acta Pharm 55:349-356. http://www.ncbi.nlm.nih.gov/pubmed/16375824

5. Sangare-Tigori B, Moukha S, Kouadio $\mathrm{HJ}$ et al (2006) Co-occurrence of aflatoxin B1, fumonisin $B 1$, ochratoxin $A$ and zearalenone in cereals and peanuts from Côte d'Ivoire. Food Addit Contam 23:1000-1007. http://www.tandfonline.com/doi/ full/10.1080/02652030500415686\#.UtU0Jydsvp8

6. Peraica M, Domijan AM, Miletić-Medved M, Fuchs $R$ (2008) The involvement of mycotoxins in the development of endemic nephropathy. Wien Klin Wochenschr 120(13-14):402-407. http://link. springer.com/article/10.1007\%2Fs00508-0080981-x
7. Klarić MS, Cvetnić Z, Pepeljnjak S, Kosalec I (2009) Co-occurrence of aflatoxins, ochratoxin A, fumonisins, and zearalenone in cereals and feed, determined by competitive direct enzyme-linked immunosorbent assay and thin-layer chromatography. Arh Hig Rada Toksikol 60:427-434. http:// www.degruyter.com/view/j/aiht.2009.60.issue-4/10004-1254-60-2009-1975/100041254-60-2009-1975.xml

8. Peraica M, Flajs D, Domijan AM et al (2010) Ochratoxin A contamination of food from Croatia. Toxins 2:2098-2105. http://www.mdpi. com/2072-6651/2/8/2098

9. IARC (1993) Ochratoxin A. IARC monographs on the evaluation of carcinogenic risks to humas. Some naturally occurring substances: food items and constituents, heterocyclic aromatic amines and mycotoxins. 56:489-521. http://monographs. iarc.fr/ENG/Monographs/vol56/mono56.pdf

10. WHO (World Health Organisation) (2001) Safety evaluation of certain mycotoxins in food. IPCS-FAO food and nutrition paper WHO, Genf. 74:281-387. http://www.inchem.org/documents/jecfa/jecmono/v47je01.htm

11. Jørgensen $K$ (2005) Occurrence of ochratoxin $A$ in commodities and processed food - $a$ review of EU occurrence data. Food Add Contam 22:26-30. http://www.tandfonline.com/doi/ pdf/10.1080/02652030500344811

12. EU (2006) Amtsblatt der Europäischen Union, Verordnung (EG) Nr.1881/2006 der Kommission zur Festsetzung der Höchstgehalte für bestimmte Kontaminanten in Lebensmitteln (Text with EEA relevance). 576(49)(L364):05-24. http://eurlex.europa.eu/JOHtml.do?uri=OJ:L:2006:364:SO M:DE:HTML, http://eur-lex.europa.eu/LexUriServ/ LexUriServ.do?uri=OJ:L:2006:364:0005:0024:DE:P DF

13. EU (2010) Amtsblatt der Europäischen Union, VERORDNUNG (EU) Nr.105/2010 DER KOMMISSION zur Änderung der Verordnung (EG) Nr.1881/2006 zur Festsetzung der Höchstgehalte für bestimmte Kontaminanten in Lebensmitteln hinsichtlich Ochratoxin A.35(53)(L35):7-8. http:// eur-lex.europa.eu/JOHtml.do?uri=OJ:L:2010:035 :SOM:DE:HTML, http://eur-lex.europa.eu/LexUriServ/LexUriServ.do?uri=OJ:L:2010:035:FULL:DE:P DF

14. EU (2006) Commission of the European Communities, Commission Recommendation on the presence of deoxynivalenol, zearalenone, ochratoxin A, T-2 and HT-2 and fumonisins in products intended for animal feeding (Text with EEA relevance). 576(49)(L229):7-9. http://eur-lex.europa.eu/JOHtml.do?uri=OJ:L:2006:229:SOM:EN: HTML, http://irmm.jrc.ec.europa.eu/EURLs/eurl mycotoxins/legislation/Pages/index.aspx, http:// eur-lex.europa.eu/LexUriServ/LexUriServ.do?uri= OJ:L:2006:229:0007:0009:EN:PDF

15. EU (2009) Amtsblatt der Europäischen Union, Verordnung (EG) Nr.386/2009 der Kommission vom 12. Mai 2009 zur Änderung der Verordnung (EG) Nr.1831/2003 des Europäischen Parlaments und des Rates hinsichtlich der Festlegung einer neuen Funktionsgruppe für Futtermittelzusatzstoffe. 52(L118):66. http://eur-lex.europa. eu/JOHtml.do?uri=OJ:L:2009:118:SOM:DE:HTML , http://eur-lex.europa.eu/LexUriServ/LexUriServ. do?uri=OJ:L:2009:118:FULL:DE:PDF
16. Walker R, Larsen JC (2005) Ochratoxin A: previous risk assessments and issues arising. Food Addit Contam 22(Suppl 1):6-9. http://www.ncbi.nlm. nih.gov/pubmed/16332615

17. Duarte SC, Lino CM, Pena A (2010) Mycotoxin food and feed regulation and the specific case of ochratoxin A: a review of the worldwide status. Food Addit Contam Part A Chem Anal Control Expo Risk Assess 27:1440-1450. http://www.ncbi. nlm.nih.gov/pubmed/20658402

18. Duarte SC, Lino CM, Pena A (2011) Ochratoxin $A$ in feed of food-producing animals: an undesirable mycotoxin with health and performance effects. Vet Microbiol 154(1-2):1-13. http:// www.sciencedirect.com/science/article/pii/ S0378113511002707

19. Duarte SC, Pena A, Lino CM (2009) Ochratoxin A non-conventional exposure sources - a review. Microchem J 93:115-120. http://www.sciencedirect.com/science/article/pii/S0026265X09000885

20. SCOOP (Scientific Cooperation Task Reports) (2002) Assessment of dietary intake of Ochratoxin $\mathrm{A}$ by the population of EU Member States. http://ec.europa.eu/food/fs/scoop/3.2.7_en.pdf, http://ec.europa.eu/food/fs/scoop/index_ en.html

21. Di Giuseppe R, Bertuzzi T, Rossi F et al (2012) Plasma ochratoxin A levels, food consumption, and risk biomarkers of a representative sample of men and women from the Molise region in Italy. Eur J Nutr 51:851-860. http://link.springer.com/ article/10.1007\%2Fs00394-011-0265-5

22. Mateo R, Medina A, Mateo EM et al (2007) An overview of ochratoxin $A$ in beer and wine. Int J Food Microbiol 119:79-83. http:// www.sciencedirect.com/science/article/pii/ S016816050700390X

23. EC SCF (European Commission's Scientific Committee on Food) (1998) Opinion of the European Commission's Scientific Committee on food on ochratoxin A. Expressed 17.09.98 - SCF. http:// ec.europa.eu/food/fs/sc/scf/out14_en.html

24. Kuiper-Goodman T, Hilts C, Billiard SM et al (2010) Health risk assessment of ochratoxin A for all age-sex strata in a market economy. Food Addit Contam Part A Chem Anal Control Expo Risk Assess 27:212-240. http://www.tandfonline. com/doi/abs/10.1080/02652030903013278?url_ ver=Z39.88-2003\&rfr_id=ori:rid:crossref.org\&rfr_ dat $=$ cr_pub\%3dpubmed\#.UtQUGydsvp8

25. JECFA (Joint FAO/WHO Expert Committee on Food Additives) (2001) WHO food additives series: 47 . Safety evaluation of certain mycotoxins in food. Ochratoxin A. http://www.inchem.org/ documents/jecfa/jecmono/v47je04.htm

26. EFSA (European Food Safety Authority) (2006) Opinion of the scientific panel on contaminants in the food chain on a request from the commission related to Ochratoxin $A$ in food. Question NEFSA-Q-2005-154. EFSA J 365:1-56. http:// www.efsa.europa.eu/en/scdocs/doc/contam_op_ ej365_ochratoxin_a_food_en.pdf

27. EFSA (European Food Safety Authority) (2010) Scientific opinion. Statement on recent scientific information on the toxicity of Ochratoxin A.EFSA panel on contaminants in the food chain. EFSA J 8:1626. http://www.efsa.europa.eu/it/search/ doc/1626.pdf 
28. Kasel U, Wichmann G, Bleck M (1999) Ochratoxin im Hausstaub. Umweltmed Forsch Prax 4(5):301303. http://www.ecomed-medizin.de/sj/ufp/Pdf/ ald/979

29. Degen GH, Meifort J, Blaszkewicz M (2005) Pilotstudie zum Biomonitoring für Ochratoxin $A$ bei Beschäftigten im Getreide- und Rohkaffee-Umschlag. Mycotoxin Res 21:168171. http://link.springer.com/article/ 10.1007\%2FBF02959256\#page-1

30. Mayer S, Gareis M, Degen GH et al (2007) Belastung durch luftgetragene Mykotoxine in Getreidelägern und Mykotoxinkonzentrationen im Blut von Getreidelagerarbeitern. Gefahrst Reinhalt Luft 67:119-125. http://www.gefahrstoffe.de/ gest/article.php?data[article_id] $=34784$

31. Tarin A, Rosell MG, Guardino X (2004) Use of high-performance liquid chromato-graphy to assess airborne mycotoxins: Aflatoxins and ochratoxin A. J Chromatogr A 1047:235-240. http:// www.sciencedirect.com/science/article/pii/ S0021967304010623

32. DFG (Deutsche Forschungsgemeinschaft) (2013) MAK- und BAT-Werte-Liste 2013. Senatskommission zur Prüfung gesundheitsschädlicher Arbeitsstoffe. Mitteilung 49. Wiley-VCH, Weinheim

33. Pfohl-Leszkowicz A, Manderville RA (2007) Ochratoxin $A$ : an overview on toxicity and carcinogenicity in animals and humans. Mol Nutr Food Res 51:61-99. http://onlinelibrary.wiley.com/ doi/10.1002/mnfr.200600137/abstract

34. Boonen J, Malysheva SV, Taevernier L et al (2012) Human skin penetration of selected model mycotoxins. Toxicology 301:21-32. http:// www.sciencedirect.com/science/article/pii/ S0300483X12002429\#

35. Pfohl-Leszkowicz A, Manderville RA (2012) An update on direct genotoxicity as a molecular mechanism of ochratoxin A carcinogenicity. Chem Res Toxicol 25:252-262. http://pubs.acs.org/doi/ abs/10.1021/tx200430f

36. Mantle PG, Faucet-Marquis V, Manderville RA et al (2010) Structures of covalent adducts between DNA and ochratoxin A: a new factor in debate about genotoxicity and human risk assessment. Chem Res Toxicol 23:89-98. http://pubs.acs.org/ doi/abs/10.1021/tx900295a

37. Al-Anati L, Petzinger E (2006) Immunotoxic activity of ochratoxin A. J Vet Pharmacol Ther 29:7990. http://onlinelibrary.wiley.com/doi/10.1111/ j.1365-2885.2006.00718.x/abstract

38. Wangikar PB, Dwivedi P, Sinha N (2004) Effect in rats of simultaneous prenatal exposure to ochratoxin A and aflatoxin B1. I. Maternal toxicity and fetal malformations. Birth Defects Res B Dev Reprod Toxicol 71:343-351. http://onlinelibrary. wiley.com/doi/10.1002/bdrb.20021/pdf

39. Hsuuw YD, Chan WH, Yu JS (2013) Ochratoxin A inhibits mouse embryonic development by activating a mitochondrion-dependent apoptotic signaling pathway. Int J Mol Sci 14:935-953. http://www.mdpi.com/1422-0067/14/1/935

40. Patil RD, Dwivedi P, Sharma AK (2006) Critical period and minimum single oral dose of ochratoxin A for inducing developmental toxicity in pregnant Wistar rats. Reprod Toxicol 22:679-687. http://www.sciencedirect.com/science/article/ pii/S0890623806001067
41. Abid S, Hassan W, Achour A et al (2003) Ochratoxin $A$ and human chronic nephropathy in Tunesia: is the situation endemic? Hum Exp Toxicol 22:7784. http://het.sagepub.com/content/22/2/77.full. pdf + html

42. Vrabcheva T, Petkova-Bocharova T, Grosso F et al (2004) Analysis of ochratoxin A in foods consumed by inhabitants from an area with balkan endemic nephropathy: a 1 month follow-up study. J Agric Food Chem 52:2404-2410. http://pubs. acs.org/doi/abs/10.1021/jf030498z

43. Fuchs R, Peraica M (2005) Ochratoxin A in human kidney diseases. Food Addit Contam 22(s1):53-57. http://www.tandfonline.com/doi/ pdf/10.1080/02652030500309368

44. Yordanova P, Wilfried K, Tsolova S, Dimitrov P (2010) Ochratoxin A and $\beta 2$-microglobulin in BEN patients and controls. Toxins 2:780-792. http://www.mdpi.com/2072-6651/2/4/780

45. Petkova-Bocharova T, Castegnaro $M$, Michelon J, Maru V (1991) Ochratoxin A and other mycotoxins in cereals from an area of Balkan endemic nephropathy and urinary tract tumours in Bulgaria. IARC Sci Publ 115:83-87. http://www.ncbi. nlm.nih.gov/pubmed/1820357

46. Castegnaro M, Canadas D, Vrabcheva T et al (2006) Balkan endemic nephropathy: role of ochratoxins A through biomarkers. Mol Nutr Food Res 50:519-529. http://onlinelibrary.wiley.com/ doi/10.1002/mnfr.200500182/abstract

47. Chernozemsky IN, Stoyanov IS, Petkova-Bocharova TK et al (1977) Geographic correlation between the occurrence of endemic nephropathy and urinary tract tumours in Vratza district Bulgaria. Int J Cancer 19:1-11. http://onlinelibrary.wiley.com/doi/10.1002/ijc.2910190102/pdf

48. Wafa EW, Yahya RS, Sobh MA et al (1998) Human ochratoxicosis and nephropathy in Egypt: a preliminary study. Hum Exp Toxicol 17:124-129. http://het.sagepub.com/content/17/2/124.full. pdf + html

49. Grollman AP, Shibutani S, Moriya M et al (2007) Aristolochic acid and the etiology of endemic (Balkan) nephropathy. Proc Natl Acad Sci U S A 104(29):12129-12134. http://www.pnas.org/content/104/29/12129.long

50. Pepeljnjak S, Klarić MŠ (2010) „Suspects“ in etiology of endemic nephropathy: aristolochic acid versus mycotoxins. Toxins 2:1414-1427. http:// www.mdpi.com/2072-6651/2/6/1414

51. Haighton LA, Lynch BS, Magnuson BA, Nestmann ER (2012) A reassessment of risk associated with dietary intake of ochratoxin A based on a lifetime exposure model. Crit Rev Toxicol 42:147168. http://informahealthcare.com/doi/pdfpl us/10.3109/10408444.2011.636342

52. Coronel MB, Sanchis V, Ramos AJ, Marin S (2010) Review. Ochratoxin A: presence in human plasma and intake estimation. Food Sci Technol Int 16:5-18. http://fst.sagepub.com/content/16/1/5 long

53. Studer-Rohr I, Schlatter J, Dietrich DR (2000) Kinetic parameters and intraindividual fluctuations of ochratoxin A plasma levels in humans. Arch Toxicol 74:499-510. http:// kops.ub.uni-konstanz.de/bitstream/handle/ urn:nbn:de:bsz:352-opus-49607/Kinetic_parameters_and_intraindividual_fluctuations of_ochratoxin_A_plasma_levels_in_humans. pdf? sequence $=1$
54. Stojkovic R, Hult K, Gamulin S, Plestina R (1984) High affinity binding of ochratoxin A to plasma constituents. Biochem Int 9:33-38. http://www. ncbi.nlm.nih.gov/pubmed/6477636

55. Hagelberg S, Hult K, Fuchs R (1989) Toxicokinetics of ochratoxin $A$ in several species and its plasma-binding properties. J Appl Toxicol 9:9196. http://onlinelibrary.wiley.com/doi/10.1002/ jat.2550090204/pdf

56. Ringot $D$, Chango A, Schneider $Y$, Larondelle $Y$ (2006) Toxicokinetics and toxicodynamics of ochratoxin A, an update. Chem Biol Interact 159:1846. http://www.sciencedirect.com/science/article/pii/S0009279705003479

57. Fuchs R, Hult K (1992) Ochratoxin A in blood and its pharmacokinetic properties. Food Chem Toxicol 30:201-204. http://www.sciencedirect.com/ science/article/pii/027869159290034l

58. Corcuera LA, Vettorazzi A, Arbillaga L et al (2012) An approach to the toxicity and toxicokinetics of aflatoxin B1 and ochratoxin A after simultaneous oral administration to fasted F344 rats. Food Chem Toxicol 50:3440-3446. http:// www.sciencedirect.com/science/article/pii/ S0278691512004620

59. Gaou I, Dubois M, Pfohl-Leszkowicz A et al (2005) Safety of Oxygreen ${ }^{\oplus}$, an ozone treatment on wheat grains. Part 1. A four-week toxicity study in rats by dietary administration of treated wheat. Food Addit Contam 22:1113-1119. http://www.tandfonline.com/doi/abs/10.1080/ 02652030500307156?journalCode=tfac19\#. UtP1iidsvp8

60. Miraglia M, Brera C, Corneli S et al (1998) Occurrence of ochratoxin $A$ in maternal blood serum, placenta and funiculum. In: Miraglia M, Egmond HP van, Brera C, Gilbert J (Hrsg) Mycotoxins and phycotoxins: developments in chemistry, toxicology and food safety. Alaken Inc, Fort Collins, S 165-179. http://www.alaken.com/myco_phyco. html

61. Zimmerli B, Dick R (1995) Determination of ochratoxin A at the ppt level in human blood, serum, milk and some foodstuffs by high-performance liquid chromatography with enhanced fluorescence detection and immune affinity column cleanup: methodology and Swiss data. J Chromatogr B Biomed Appl 666:85-99. http:// www.sciencedirect.com/science/article/pii/ 037843479400569Q\#

62. Gekle M, Sauvant C, Schwerdt G (2005) Ochratoxin $A$ at nanomolar concentrations: a signal modulator in renal cells. Mol Nutr Food Res 49:118130. http://onlinelibrary.wiley.com/doi/10.1002/ mnfr.200400062/pdf

63. Li S, Marquardt RR, Frohlich AA et al (1997) Pharmacokinetics of ochratoxin A and its metabolites in rats. Toxicol Appl Pharmacol 145:82-90. http://www.sciencedirect.com/science/article/ pii/S0041008X97981552

64. Wu Q, Dohnal V, Huang L et al (2011) Metabolic pathways of ochratoxin A. Curr Drug Metab12:1-10. http://www.eurekaselect. com/73315/article

65. Grenier B, Applegate TJ (2013) Modulation of intestinal functions following mycotoxin ingestion: meta-analysis of published experiments in animals. Toxins 5:396-430. http://www.mdpi. com/2072-6651/5/2/396 
66. Størmer FC, Hansen CE, Pedersen Jl et al (1981) Formation of 4R- and 4S- 4-hydroxyochratoxin A from ochratoxin $A$ by liver microsomes from various species. Appl Environ Microbiol 42:10511056. http://aem.asm.org/content/42/6/1051.abstract

67. Gautier JC, Richoz J, Welti DH et al (2001) Metabolism of ochratoxin $\mathrm{A}$ : absence of formation of genotoxic derivatives by human and rat enzymes. Chem Res Toxicol 14:34-45. http://pubs.acs.org/ doi/abs/10.1021/tx000070j

68. Gross-Steinmeyer KG, Weymann J, Hege HG, Metzler M (2002) Metabolism and lack of DNA reactivity of the mycotoxin ochratoxin A in cultured rat and human primary hepatocytes. J Agric Food Chem 50:938-945. http://pubs.acs.org/doi/ abs/10.1021/jf0111817

69. Pinelli E, Adlouni CE, Pipy B et al (1999) Roles of cyclooxygenase and lipoxygenases in ochratoxin A genotoxicity in human epithelial lung cells. Environ Toxicol Pharmacol 7:95-107. http:// www.sciencedirect.com/science/article/pii/ S1382668999000083

70. Mally A, Dekant W (2009) Mycotoxins and the kidney: modes of action for renal tumor formation by ochratoxin A in rodents. Mol Nutr Food Res 53:467-478. http://onlinelibrary.wiley.com/ doi/10.1002/mnfr.200800149/abstract;jsessionid $=A 8835 A 4 A 189 F 4 B F 3 E E 03655233 C C 8 B 42 . f 01 t 01$

71. Mally A (2012) Ochratoxin A and mitotic disruption: mode of action analysis of renal tumor formation by ochratoxin A. Toxicol Sci127:315330. http://toxsci.oxfordjournals.org/content/127/2/315.full

72. Mally A, Pepe G, Ravoori S et al (2005) Ochratoxin A causes DNA damage and cytogenetic effects but no DNA adducts in rats. Chem Res Toxicol18:1253-1261. http://pubs.acs.org/doi/ abs/10.1021/tx049650x

73. Kamp HG, Eisenbrand G, Janzowski C et al (2005) Ochratoxin A induces oxidative DNA damage in liver and kidney after oral dosing to rats. Mol Nutr Food Res 49:1160-1167. http://onlinelibrary.wiley.com/doi/10.1002/mnfr.200500124/pdf

74. Scott PM (2005) Biomarkers of human exposure to ochratoxin A. Food Addit Contam 22(s1):99-107. http://www.tandfonline.com/doi/ pdf/10.1080/02652030500410315

75. Duarte SC, Pena A, Lino CM (2011) Human ochratoxin A biomarkers - from exposure to effect. Crit Rev Toxicol 41:187-212. http://informahealthcare.com/doi/abs/10.3109/10408444.2010.529103

76. Coronel MB, Marin S, Tarragó M et al (2011) Ochratoxin $A$ and its metabolite ochratoxin alpha in urine and assessment of the exposure of inhabitants of Lleida. Spain. Food Chem Toxicol 49:1436-1442. http://www.sciencedirect.com/ science/article/pii/S0278691511001220

77. Breitholtz-Emanuelsson A, Olsen M, Oskarsson A et al (1993) Ochratoxin A in cow's milk and in human milk with corresponding human blood samples. J AOAC Int 76:842-846. http://www.ncbi. nlm.nih.gov/pubmed/8374329

78. Munoz K, Wollin K-M, Kalhoff H, Degen GH (2013) Zum Vorkommen des Mykotoxins Ochratoxin $A$ in Muttermilchproben aus Deutschland. Gesundheitswesen 75:194-191. https:// www.thieme-connect.com/ejournals/html/ 10.1055/s-0033-1341442
79. Blaszkewicz M, Baumhoer G, Butte, W (2010) Ochratoxin A. In: Angerer J, Hartwig A (Hrsg) Analytische Methoden zur Prüfung gesundheitsschädlicher Arbeitsstoffe. Analysen in biologischem Material. 19. Lieferung. Wiley-VCH, Weinheim. http://onlinelibrary.wiley.com/ doi/10.1002/3527600418.bi30347d0019/pdf

80. Meulenberg EP (2012) Immunochemical methods for ochratoxin A detection: a review. Toxins 4:244-266. http://www.mdpi.com/2072$6651 / 4 / 4 / 244$

81. Märtlbauer E, Usleber E, Dietrich R, Schnei$\operatorname{der} E$ (2009) Ochratoxin A in human blood serum - retrospective long-term data. Mycotoxin Res 25:175-186. http://link.springer.com/article/ 10.1007\%2Fs12550-009-0025-z

82. Köller G, Rolle-Kampczyk U, Lehmann I et al (2004) Determination of ochratoxin A in small volumes of human blood serum. J Chromatogr B Analyt Technol Biomed Life Sci 804:313-317. http://www.sciencedirect.com/science/article/ pii/S1570023204000649

83. Erkekoğlu P, Sabuncuoğlu S, Aydin S et al (2010) Determination of seasonal variations in serum ochratoxin A levels in healthy population living in some regions of Turkey by enzyme-linked immunosorbent assay. Toxicon 55:507-513. http:// www.sciencedirect.com/science/article/pii/ S0041010109004760

84. Ruprich J, Ostrý V (1993) Health risk assessment of the mycotoxin ochratoxin A to humans: Czech Republic - Brno - 1991/92. Cent Eur J Public Health 1:86-93. http://apps.szu.cz/svi/cejph/archiv/1993-2-05.pdf

85. Märtlbauer E, Usleber E, Straka M (1996) Ochratoxin A im Serum eines Lehrstuhlkollektivs: 1990-1995. Proceedings, 18. Mykotoxin Workshop, 10-12 June 1996, Kulmbach, Germany: 97101. http://d-nb.info/953992012/04

86. Gilbert J, Brereton P, MacDonald S (2001) Assessment of dietary exposure to ochratoxin $A$ in the UK using a duplicate diet approach and analysis of urine and plasma samples. Food Addit Contam 18(12):1088-1093. http://www.tandfonline.com/ doi/abs/10.1080/02652030110070030?journalCode $=$ tfac19\#.UtP3bSdsvp8

87. Palli D, Miraglia M, Saieva C et al (1999) Serum Levels of ochratoxin $A$ in healthy adults in Tuscany: correlation with individual characteristics and between repeat measurements. Cancer Epidemiol Biomarkers Prev 8:265-269. http://www.tandfonline.com/doi/abs/10.1080/ 02652030110070030?journalCode $=$ tfac19\#. UtP3bSdsvp8

88. Breitholtz A, Olsen M, Dahlback A, Hult K (1991) Plasma ochratoxin A levels in three Swedish populations surveyed using an ion-pair HPLC technique. Food Addit Contam 8:183-192. http:// www.tandfonline.com/doi/abs/10.1080/ 02652039109373968? journalCode=tfac19\#. UtAJZSdsvp8

89. Peraica M, Domijan AM (2001) Mycotoxins in food and human health. Arh Hig Rada Toksikol 52:23-35

90. Gareis M, Rosner H, Ehrhardt S (2000) Blood serum levels of ochratoxin $A$ and nutrition habits. Arch Lebensmittelhygiene 51:108-110. http:// www.zbmed.de/ccmedimages/2000/11897.pdf
91. Rosner H, Rohrmann B, Peiker G (2000) Ochratoxin $A$ in human serum. Arch Lebensmittelhygiene 51(4-5):104-107. http://www.zbmed.de/ccmedimages/2000/11897.pdf

92. Miraglia M, Brera C, Colatosti M (1996) Application of biomarkers to assessment of risk to human health from exposure to mycotoxins. Microchem J 54:472-477. http://www.sciencedirect.com/ science/article/pii/S0026265X96901241

93. Studer-Rohr I (1995) Ochratoxin A in humans: exposure, kinetics and risk assessment. Dissertation ETH Zürich (DissETHNo. 11071). doi:10.3929/ ethz-a-001455649. Available via ETH Institutional Repository. http://e-collection.ethbib.ethz.ch/ view/eth:22417, http://e-collection.library.ethz. ch/eserv/eth:22417/eth-22417-02.pdf

94. Thuvander A, Paulsen JE, Axberg K et al (2001) Levels of ochratoxin A in blood from Norwegian and Swedish blood donors and their possible correlation with food consumption. Food Chem Toxicol 39:1145-1151. http://www.sciencedirect. com/science/article/pii/S0278691501000801

95. Munoz K, Vega M, Rios G et al (2006) Preliminary study of ochratoxin $A$ in human plasma in agricultural zones of Chile and its relation to food consumption. Food Chem Toxicol 44:1884-1889. http://www.sciencedirect.com/science/article/ pii/S027869150600158X

96. Coronel MB, Sanchis V, Ramos AJ, Marin S (2009) Assessment of the exposure to ochratoxin $A$ in the province of Lleida, Spain. Food Chem Toxicol 47:2847-2852. http://www.sciencedirect.com/ science/article/pii/S027869150900413X

97. Kommission Human-Biomonitoring des Umweltbundesamtes (1996) Konzept der Referenz und Human-Biomonitoring-Werte (HBM) in der Umweltmedizin. Bundesgesundheitsbl Gesundheitsforsch Gesundheitsschutz 39(6):221-224

98. Kommission Human-Biomonitoring des Umweltbundesamtes (2009) Addendum zum Konzept der Referenz- und Human-Biomonitoring-Werte (HBM) in der Umweltmedizin. Bundesgesundheitsbl Gesundheitsforsch Gesundheitsschutz 52(8): 874-877. https://www.umweltbundesamt. de/sites/default/files/medien/pdfs/addendum_ ref_werte_2009.pdf 